\title{
CONSIDERAÇÕES A RESPEITO DO EXISTENCIALISMO NA OBRA DE CLARICE LISPECTOR*
}

\author{
Maria Elisa de OLIVEIRA**
}

RESUMO: Tendo por base a exegese que o crítico Benedito Nunes realizou a respeito da obra de Clarice Lispector, procuraremos, neste artigo, fazer algumas considerações em torno daquilo que comumente se denominou existencialismo na produção ficcional de Clarice Lispector. Ao mesmo tempo, chamaremos a atenção para aqueles aspectos da sua obra que levam a marca de sua originalidade e que fazem com que a sua produção ficcional se afaste de um certo tipo de existencialismo.

UNITERMOS: Filosofia; literatura; existencialismo; enfoque interdisciplinar; a náusea; a angústia; perspectiva mística; Clarice Lispector.

A tarefa de analisar a obra de Clarice Lispector exige um grande fôlego, já que a autora nos deixou uma vasta produção ficcional nos mais variados gêneros: romances, contos, crônicas e até mesmo histórias infantis.

Inicialmente, gostaríamos apenas de situar, em linhas gerais, a posição que a produção ficcional clariceana ocupa no âmbito e no contexto da literatura brasileira contemporânea; ao mesmo tempo, assinalaremos alguns aspectos biográficos revelados em entrevistas, por ela mesma. Com isto, esperamos obter uma visão rápida não só do seu trabalho como também de sua figura.

* Este texto foi elaborado a partir de uma palestra proferida no auditório da Bilbioteca Mário de Andrade, dentro do ciclo de conferência Introdução à Filosofia da Arte, em março de 1987.

** Departamento de Filosofia - Faculdade de Filosofia e Ciências - UNESP - 17500 Marília - SP. 
Durante seus trinta anos de atividade literária, caracterizada por um árduo e apaixonante trabalho com as palavras e a linguagem, Clarice Lispector escreveu mais de quinze obras.

A primeira obra publicada foi o romance Perto do Coração Selvagem, em 1944. Na época, a autora contava apenas dezoito anos de idade - uma estréia bastante precoce. Para alguns críticos, este romance é considerado o mais significativo, porque paradigma de todos' os outros (Nota A). Nesta primeira experiência Clarice encontrou algumas dificuldades editoriais para publicar o seu livro. A partir daí, até a última obra, $A$ hora da estrela, publicada em 1977, dois meses antes de falecer, uma série de outros livros se seguiram, sem muitos entraves.

Como obras póstumas surgiram: Um sopro de vida (pulsações), A bela e a fera (contos) e $A$ descoberta do mundo. Este último reúne todas as crônicas que Clarice escreveu para o Jornal do Brasil, aos sábados, entre agosto de 1967 e dezembro de 1973.

A precocidade de Clarice Lispector surge, contudo, bem antes da publicação de seu primeiro romance. Desde cedo, com apenas sete anos, Clarice já mandava pequenas histórias para uma seção infantil de um jornal do Recife, que, aliás, nunca foram publicadas. A esse respeito a própria autora comenta:

"(...) eu as enviava para a página infantil das quintas-feiras do jornal do Recife, e nenhuma foi jamais publicada. E era fácil de ver porquê. Nenhuma contava propriamente uma história. Eu lia as que eles publicavam e todas relatavam um acontecimento. Mas se eles eram teimosos eu também" (10, p. 17).

Como podemos notar neste depoimento, já desde tenra idade Clarice revela um traço insistente que se tornaria marca essencial de sua produção literária. Realmente, em lugar de um texto que narre fatos e acontecimentos, ela preferirá sempre escutar as ressonâncias dos fatos na consciência do indivíduo.

Ao lado desta característica, uma outra igualmente importante sempre mereceu o destaque dos estudiosos desta autora. Trata-se do fato de Clarice Lispector nunca ter separado sua própria vida e destino, do exercício da linguagem. Eis o que ela mesma nos revela numa bela e emocionante confissão:

"Há três coisas para as quais nasci e para as quais eu dou minha vida. Nasci para amar os outros, nasci para escrever e nasci para criar meus filhos. (...) A palavra é o meu domínio sobre o mundo.

Eu tive desde a minha infância várias vocações que me chamavam ardentemente. Uma das vocações era escrever. E não sei porque, foi esta a que segui. Talvez porque para as outras vocações eu precisaria de um longo aprendizado, enquanto que para escrever o aprendizado é a própria vida se vivendo em nós e ao redor de nós. É que não sei estudar. Adestrei-me desde os sete anos de idade para que um dia eu tivesse a língua em meu poder. E, no entanto, cada vez que vou escrever, é 
como se fosse a primeira vez. Essa capacidade de me renovar toda à medida que $\mathrm{o}$ tempo passa é o que eu chamo de viver e escrever" (10, p. 135$)$.

Das informações biográficas a respeito de Clarice Lispector guarda-se a impressão de que tudo aconteceu, de fato, muito cedo em sua vida: o prêmio Graça Aranha, com seu primeiro romance; o seu casamento, em 1943, com um diplomata (a partir de 1944 Clarice viverá longo tempo fora do Brasil, sendo que seus dois filhos nascem no exterior); a formação no curso de direito em 1944, no mesmo ano em que publica Perto do coração selvagem e, finalmente, seu próprio falecimento ocorrido no dia 7 de dezembro de 1977, faltando apenas três dias para completar cinqüienta e dois anos. A propósito desta data, um intrigante comentário de Clarice se revelou, ao final, vaticinador... Em algumas entrevistas que a escritora manteve com Haydée Jofre Barroso (Nota B), algum tempo antes de falecer, num determinado momento a entrevistadora indaga:

"Esqueci-me de perguntar quando você nasceu.

- Nasci em Tchetchelnik, Ucrânia, no dia 10 de dezembro.

Meus pais estavam a caminho do Brasil quando precisaram fazer uma pequena parada nesta cidade para que eu nascesse; assim, cheguei ao Brasil com dois meses de idade. E não sei porque sempre pensei que também algum dia de dezembro, morreria. Seria como encerrar um ciclo, você me entende? (grifo nosso)" (1, p. 3).

Quanto à receptividade da crítica brasileira à obra de Clarice Lispector, podemos notar, de uma maneira geral, que ela foi sempre bastante favorável. Desde a sua estréia em 1944, com Perto do coração selvagem, até Um sopro de vida (1978), a maioria dos críticos tem reagido com entusiasmo (Nota C). Para destacar apenas um exemplo, uma das primeiras vozes de crítico a saudar Perto do coração selvagem foi Antonio Candido, que reconheceu, neste romance, a extraordinária capacidade da jovem estreante em estender "o domínio da palavra sobre regiões mais complexas e mais inexprimíveis" $(4$, p. 126). Essa busca na tentativa de exprimir o inexprimível e de "dizer o indizível" faz com que a obra de Clarice se insira entre aquelas que, na época moderna, salientaram o aspecto do paradoxo da linguagem, que pode se revelar, ao mesmo tempo, um fracasso e um triunfo. A este respeito, a própria autora medita numa bela passagem:

"Eu tenho à medida que designo - e este é esplendor de se ter uma linguagem. Mas eu tenho muito mais à medida que não consigo designar. A realidade é a matéria-prima, a linguagem é o modo como vou buscá-la - e como não acho. Mas é do buscar e não achar que nasce o que eu não conhecia, e que instantaneamente reconheço. A linguagem é o meu esforço humano. Por destino tenho que ir buscar e por destino volto com as mãos vazias. Mas - volto com o indizível. O indizível só me poderá ser dado através do fracasso da minha 
linguagem. Só quando falha a construção, é que obtenho o que ela não conseguiu" (9, p. 20).

Sem pretender propor aqui uma definição para o termo existencialismo, já que a tarefa de definir esse termo, em todos os seus aspectos, eliminando também as idéias fantasiosas e preconcebidas (Nota D), demandaria tempo e seria muito complexa, aceitamos como saída para essa dificuldade a sugestão apresentada por Jean Wahl: em lugar de propor uma definição, seria conveniente sugerir alguns temas e conceitos ou mesmo, enumerar algumas experiências a partir das quais as chamadas filosofias da existência iniciaram sua reflexão $(18$, p. 11$)$.

Sobre a questão do existencialismo na obra de Clarice Lispector, quase todos os críticos notaram uma afinidade marcante entre a obra ficcional desta escritora e o existencialismo. Foi, no entanto, Benedito Nunes quem, de maneira completa, formulou a recomposição de um quadro temático-filosófico da romancista em seus artigos e ensaios, depois reassumidos em seus livros (Nota E). De nítida inspiração filosófica, o crítico paraense realizou, até o presente, definitiva interpretação das obras de Clarice Lispector. É difícil, pois, uma vez que foi empreendida esta leitura penetrante, acrescentar algo com a insenção de quem vai aqui encontrar filões ainda intocados. De modo que, neste artigo, nossas considerações com freqüência serão iluminadas, em particular, pela exegese do crítico paraense.

Foi Benedito Nunes quem tentou demonstrar, exaustivamente, ao longo de suas análises, que o desenvolvimento de certos temas importantes encontrados na ficção clariceana, principalmente na escala do romance, insere-se no contexto das filosofias da existência. São suas palavras:

\begin{abstract}
"Não se pretende afirmar, com isso, nem que a ficcionista vá buscar as situações típicas de seus personagens na filosofia existencial, nem que as intenções fundamentais de sua prosa só desse conjunto de doutrinas recebe o impulso extraartístico que as justifica e anima. No entanto, é sempre possível encontrar, na literatura de ficção, (...) uma concepção-de-mundo, inerente à obra considerada em si mesma, concepção esta que deriva da atitude criadora da artista, configurando e interpretando a realidade. Qualquer que seja a posição filosófica da escritora, o certo é que a concepção-do-mundo de Clarice Lispector tem marcante afinidade com a filosofia da existência. (...)" (14, p. 94).
\end{abstract}

Ora, o caminho escolhido pelo crítico paraense vai de encontrar à sugestão de Jean Wahl, anteriormente mencionada, ou seja, desentranhar alguns temas nos textos clariceanos que possam se aproximar daqueles que ocuparam a mente dos filósofos da existência. Entre eles (Nota F), vejamos o que acontece com o tema da náusea e da angústia. 
Constatamos, facilmente, que o tema da náusea e da angústia é recorrente na obra de Clarice Lispector, aparecendo constantemente não só nos romances mas também nos contos. Se tomarmos o conto "Amor", de Laços de Família (1960), e o romance A náusea (1938), de Jean-Paul Sartre, notaremos que a descrição da experiência da náusea coincide em ambos em muitos aspectos. Contudo, devemos ter muito cuidado quando fazemos este tipo de aproximação. Nunca se deve esquecer que a escritora brasileira jamais expressou o desejo de criar um sistema, qualquer que seja ele, chegando mesmo a se irritar quando a chamavam de intelectual, demonstrando até certa aversão em assumir como profissão a "carreira" de escritora. Com Sartre ocorre o contrário: o filósofo francês várias vezes expressou suas idéias filosóficas em obras de ficção, como é o caso de $A$ náusea, que acabamos de citar.

No entanto, muitos registros específicos encontrados na obra de Clarice Lispector podem estar intimamente ligados a certos tópicos da filosofia da existência e, mais particularmente, ao existencialismo sartreano. Contudo, esse relacionamento não implica admitir-se uma interferência direta de uma filosofia sobre a romancista. Trata-se apenas, como lembra Benedito Nunes, de uma afinidade concretizada no âmbito da concepção-demundo de Clarice, mas que não a determina de fora para dentro.

Com estas ressalvas, diríamos que a experiência da náusea teve, tanto para Sartre quanto para Clarice Lispector, um significado privilegiado, não se tratando apenas de um mero distúrbio fisiológico, mas de uma experiência que possui um alcance revelador. Ela revela, mais exatamente, algo que está além do seu significado imediato e limitado.

No caso do romance sartreano, a personagem Roquentin conta como lhe aconteceu, de forma gradual, o desvelamento - "descortínio", usando um termo que Clarice gosta de empregar - do sentido da existência no seu aspecto fáctico, em sua verdade fundamental. Nesta trama, o fio condutor que orienta a personagem reside na experiência singular e privilegiada da náusea (3, p. 13-25).

Todo o romance de Sartre obedece enfim a uma intuição básica, ou seja, a de que a existência humana é gratuita, contingente e desprovida de qualquer sentido. Esta descoberta será vivenciada por Roquentin num dia em que ele se encontra sentado num banco de jardim público.

No conto "Amor", a personagem Ana também passa pela mesma experiência, num dia em que ela se acha sentada num banco de um jardim público (Jardim Botânico), e a revelação plena da náusea se dá em condições bastante análogas. Evidentemente, a ação é muito mais concentrada, já que se trata de um conto e não de um romance. Eis alguns trechos colhidos, respectivamente, do romance A náusea e do conto "Amor", de Laços de Familia:

"Abandonava-me no banco, atordoado, afligido por essa profusão de seres sem
origem: eclosões por todo lado, desabrochamentos; meus ouvidos zumbiam de
existência, minha própria carne palpitava e se entreabria, se abandonava à
germinação universal: era repugnante. 'Mas por que', pensei, 'por que tantas 
existências já que todas se parecem?' Para que tantas árvores, todas iguais? Tantas existências fracassadas e obstinadamente recomeçadas - como os esforços desajeitados de um inseto caído de costas? (Eu era um desses esforços). Aquela abundância não dava impressão de generosidade, ao contrário. Era melancólica, miserável, estorvada por si mesma. Aquelas árvores, aqueles grandes corpos canhestros..." (16, p. 136).

" (...) atravessou os portões do Jardim Botânico.

Andava pesadamente pela alameda central, entre os coqueiros. Não havia ninguém no jardim. Depositou os embrulhos na terra, sentou-se no banco de um atalho e ali ficou muito tempo. (...) Ao seu redor havia ruídos serenos, cheiro de árvores, pequenas surpresas entre os cipós. Todo o jardim triturado pelos instantes já mais apressados da tarde. De onde vinha o meio sonho pelo qual estava rodeada? Como por um zunido de abelhas e aves. Tudo era estranho, suave demais, grande demais. (...)

Inquieta olhou em torno. Os ramos se balançavam, as sombras vacilavam no chão. Um pardal ciscava na terra. E de repente, com mal-estar pareceu-lhe ter caído numa emboscada. Fazia-se no jardim um trabalho secreto do qual ela começava a se aperceber" (6, p. 23).

\section{UM OUTRO ASPECTO: O LADO MÍSTICO}

Focalizando, contudo, a produção ficcional de Clarice Lispector de 1944 até, pelo menos, 1964 veremos, como observam alguns críticos, que o sentido da experiência da náusea sofre uma transformação passando a assumir uma outra função, bastante diferente daquela revelada pelo existencialismo sartreano.

Aqui entra a importância do quinto romance de Clarice Lispector, A paixão segundo G.H., escrito inteiramente em primeira pessoa. A personagem-narradora G.H., identificada até o final apenas pelas iniciais, vive uma experiência insólita, provocada por um acontecimento banal, cujo sentido último vai estar muito próximo daquilo que chamaríamos de o "indizível" e o "inefável". Esmagando uma barata na porta do guardaroupa, o confronto com o inseto que agoniza marca um momento decisivo de ruptura na vida de G.H. A partir desse momento o cotidiano da personagem-narradora se desestabiliza e se desorganiza até atingir um desmoronamento completo. Fascinada e, ao mesmo tempo, nauseada, nesse instante de confronto se inicia uma metamorfose interior que vai absorver G.H., mergulhando-a num êxtase selvagem.

Para Benedito Nunes o estado de náusea terá, especialmente neste romance, uma função espiritual marcante, a ponto do crítico caracterizar a experiência de G.H. como sendo essencialmente mística, apesar de heterodoxa (14, p. 103-12).

Olga Borelli, que, por sua vez, conviveu intensamente não só com a própria Clarice sendo sua secretária e amiga por vários anos - mas também com os textos (Nota G) da 
escritora, confirma a opinião da maioria dos críticos que encontra uma certa dimensão mística na sua obra. Eis o comentário de Olga Borelli:

"Sem qualquer vinculação explícita, dava a impressão de sempre se achar em estado de questionamento: Deus, morte, matéria, espírito, eram objeto de interrrogação, de perplexidade, que nem em conversas ela deixava de expressar. (...) É impossível chegar a uma definição de suas crenças religiosas, pois as tinha. O que fica é o nítido traçado de seu itinerário espiritual, cujo melhor testemunho é o seu próprio Texto" (2, p. 18).

No caso de $A$ paixão, é difícil discordar da opinião de Benedito Nunes quando este afirma que a personagem-narradora G.H., vencida pela atração dessa realidade impessoal, desse núcleo, desse neutro representado pela barata e sua massa branca, "cede", "se entrega" e "se perde" (14, p. 103-12). Nesta experiência insólita, a personagem sacrifica (paixão) a sua identidade pessoal, em nome de uma identidade mais universal e abrangente.

O caminho em direção a essa existência impessoal se faz e se realiza como uma verdadeira ascese: a personagem-narradora renuncia a tudo (identidade, classe social, cultura, sentimentações etc.) e experimenta, através de várias e diferentes reduções, uma perda e um esvaziamento do $E u$.

Neste aspecto, diz-se que a aproximação que se costuma fazer entre a experiência de G.H. e o ascetismo - método místico que objetiva, fundamentalmente, ao sacrifício do $E u$ numa tentativa de superar as limitações do egoísmo que separam o indivíduo da totalidade - é bastante apropriada.

Ora, a personagem G.H. procurará completar o estado de união total com a realidade mais originária e fundamental, através da manducação da barata - paródia grotesca da comunhão cristã - cujo fim seria consumar o sacrifício do $E u$. No entanto, no momento de extremo desprezo pela pessoa, sobrevém à personagem um novo acesso de náusea, tal como no início, interrompendo assim o êxtase a que deu origem:

"Crispei minhas unhas na parede: eu sentia agora o nojento na minha boca, e então comecei a cuspir, a cuspir furiosamente aquele gosto de coisa nenhuma, gosto de um nada que no entanto me parecia quase adocicado como certas pétalas de flor, gosto de mim mesma - eu cuspia a mim mesma sem chegar jamais ao ponto de sentir que enfim tivesse cuspido minha alma toda" $(9$, p. 168).

Assim, se pela náusea G.H. saíra de seu mundo, pela náusea também ela retornaria à normalidade do cotidiano, retomando seu lugar no mundo humano, com a sua organização e segurança: 
"E, como quem volta de uma viagem, voltei a me sentar quieta na cama. Eu que pensara que a maior prova de transmutação de mim mesma, seria botar na boca a massa branca de barata" (9, p. 168-9).

No caso de Clarice Lispector, é preciso tomar cuidado para não identificar a sua tentativa de traduzir o inefável e "dizer o indizível" com a experiência dos místicos, em geral. Isto porque o divino para a escritora brasileira é o real de alguma maneira (imanência) e o caminho para atingi-lo é o oposto daquele vôo pleno de esperança de que falava, por exemplo, San Juan de la Cruz e Santa Teresa de Ávila (Nota H). Neste sentido, ao invés de tentar transcender a sua humanidade, a personagem-narradora de $A$ paixão irá recuar até o irredutível (trans-descendência de que fala Benedito Nunes $(14$, p. 138), afastando de si todas as camadas superpostas pela civilização, a fim de perceber a identidade de tudo. Já em seu primeiro romance, Perto do coração selvagem, a personagem Joana chegara à verdade última de que: "Tudo é um, tudo é um..., entoara" $(11$, p. 40).

Em suma, se compararmos a experiência da náusea dos dois personagens (Roquentin e G.H.) teríamos que concordar com a análise de Benedito Nunes (14, p. 104), segundo a qual em nenhum momento o personagem sartreano se deixa absorver completamente por esta experiência, mantendo-se sempre lúcido ou, pelo menos, à beira do mergulho no "não-entendimento" dos místicos.

Em outras palavras, a aproximação entre a obra de Clarice Lispector e o existencialismo sartreano, ensaiada por alguns críticos e, em muitos aspectos, aceitável, não impede que a escritora brasileira, como bem lembra o crítico paraense $(14$, p. 109), recupere a originalidade de sua criação, afastando-se pela via mística de um certo tipo de reflexão a respeito da existência humana.

\section{NOTAS}

A. Esta é a opinião, por exemplo, de Haroldo de Campos, que afirma: “(...) Perto do coração selvagem, o primeiro e para mim, persistentemente, o mais significativo e paradigmal de seus livros, (...)" (15, p. 14).

B. Clarice Lispector cedeu algumas entrevistas que depois foram sintetizadas, reproduzidas e divulgadas num jornal de Buenos Aires (1), exatamente um ano após a sua morte.

C. Sugerimos a leitura da obra de Olga de Sá (15. p. 23-72), já que a autora realiza um exame e um levantamento exaustivos do percurso literário de Clarice Lispector junto à crítica. $\mathrm{O}$ resultado é um quadro completo, jamais feito entre nós.

D. A respeito de certas idéias fantasiosas que encobrem o verdadeiro significado do termo existencialismo, declaramos a nossa surpresa quando terminamos a leitura de uma pequena nota, publicada num jornal de São Paulo. Diz a nota:

"Filosófico 
Como resposta à onda dark do ano passado, este ano temos o existencialismo como tema de inverno. Muito cinza, preto e branco mesclados em listras e xadreses, evocando a atmosfera boêmia da escola do filósofo Jean-Paul Sartre.

O existencialismo é uma das propostas da coleção de inverno de (...) tecidos. E está presente nas camisetas das etiquetas (...), (...), entre outras que começam a chegar nas lojas este mês" (5, p. 11).

E. Estamos nos referindo aos livros $(13,14)$ do mesmo autor.

F. Além destes temas, Benedito Nunes irá apontar outros: o fracasso, o nada, a linguagem, a comunicação das consciências (Cf. do mesmo autor (14, p. 93).

G. Olga Borelli foi responsável pela ordenação dos manuscritos de $(11,12)$ de Clarice Lispector, publicados postumamente, e autora do livro (2).

H. Dois grandes místicos cristãos do século XVI, ambos nascidos na Espanha, deixaram uma obra considerada de grande valor, dentro da Literatura mística de todos os tempos e lugares. Ver, por exemplo, a este respeito, o livro de Dora Ferreira da Silva (17).

OLIVEIRA, M.E. de - Considérations sur l'existencialisme dans l'oeuvre de Clarice Lispector. Trans/Form/Ação, São Paulo, 12: 47-56, 1989.

RÉSUMÉ: En prenant pour base l'exégèse que M. Benedito Nunes a fait sur l'oeuvre de Clarice Lispector, nous ferons ici, des considérations sur ce qu'on appelle existencialisme dans la production littéraire de Clarice Lispector. L'on doit aussi souligner quelques aspects marcant l'originalité de son oeuvre qui l'eloignent d'un certain type d' existencialisme.

UNITERMES: Philosophie; littérature; examen interdisciplinaire; la nausée; l'angoisse; mysticisme; Clarice Lispector

\section{REFERÊNCIAS BIBLIOGRÁFICAS}

1. BARROSO, J. - Clarice Lispector. Clarín, Cultura Y Nacion. Buenos Aires, 7 dez. 1978. p. 2-3.

2. BORELLI, O. - Clarice Lispector; esboço para um possível retrato. Rio de Janeiro, Nova Fronteira, 1981.

3. BORNHEIM, G. - Sartre; metafísica e existencialismo. 2. ed. São Paulo, Perspectiva, 1971.

4. CÂNDIDO, A. - Vários escritos. 2 ed. São Paulo, Duas Cidades, 1977.

5. FILOSÓFICO - Folha de São Paulo, São Paulo, 8 mar. 1987. Suplemento Casa \& Companhia.. 
6. LISPECTOR, C. - Amor. In:_- Laços de família; contos. 9. ed. Rio de Janeiro, J. Olympio, 1977.

7. LISPECTOR, C. - A bela e a fera; contos. Rio de Janeiro, Nova Fronteira, 1979.

8. LISPECTOR, C. - A descoberta do mundo; crônicas. Rio de Janeiro, Nova Fronteira, 1984.

9. LISPECTOR, C. - A paixão segundo G.H.; romance. 5. ed. Rio de Janeiro, J. Olympio, 1977.

10. LISPECTOR, C. - Para não esquecer; crônicas. São Paulo, Ática, 1978.

11. LISPECTOR, C. - Perto do coração selvagem; romance. 6 ed. Rio de Janeiro, J. Olympio, 1977.

12. LISPECTOR, C. - Um sopro de vida; Pulsações. Rio de Janeiro, Nova Fronteira, 1978.

13. NUNES, B. - Leitura de Clarice Lispector. São Paulo, Quiron, 1973.

14. NUNES, B. - O mundo imaginário de Clarice Lispector. In: — $-O$ dorso do tigre. São Paulo, Perspectiva, 1986.

15. SÁ, O.de. - A escritura de Clarice Lispector. Petrópolis, Vozes; Lorena, Faculdades Integradas Tereza d'Avila, 1979.

16. SARTRE, J.P. - A náusea. Trad. de Rita Braga. Rio de Janeiro, Nova Fronteira, 1983.

17. SILVA, D. da - A poesia mística de San Juan de la Cruz. Trad. de Dora Ferreira da Silva; estudos introdutórios de Hubert Lepargneur e Dora Ferreira da Silva. Edição bilíngüe. São Paulo, Cultrix, 1984.

18. WAHL, J. - Les philosophies de l'existence. Paris, Armand Colin, 1954. 